\title{
Teaching the Mechanism of Horizontal and Vertical Supply Chain Coordination
}

\author{
Xun Xu \\ College of Business Administration \\ California State University, Stanislaus, United States \\ Email: xxu@csustan.edu
}

\begin{abstract}
Coordinating stakeholder's actions in a supply chain provides an efficient approach to enhance supply chain performance and win today's fierce competition in the market. Using quantitative examples is proved to be an efficient pedagogical methodology to motivate students learning and facilitate students' in-depth knowledge in supply chain management education. This study provides six quantitative supply chain horizontal and vertical coordination examples, which aim to increase the profit of the whole supply chain. Each example describes the supply chain coordination model with the background of certain supply chain features. Numerical examples and sensitivity analysis are provided to illustrate the benefits of supply chain coordination visually. These examples serve as supplements of an introductory operations management/supply chain management course when the supply chain management fundamentals are taught. They offer a unique viewpoint and roadmap for instructors teaching operations management / supply chain management related courses.
\end{abstract}

Keywords: Supply Chain Management, Supply Chain Coordination, Optimization

\section{INTRODUCTION}

The increasingly fierce competition in today's market happens between supply chains versus supply chains, instead of between individual companies (Xu and Gursoy, 2015). The improved operations performance is essential for a supply chain, which can be achieved by supply chain management. Supply chain management is an important topic in operations management course, and even becomes an independent required course for students majored in operations management in many colleges (Anderson and Morrice, 2000; Akalin et al., 2016).

Supply chain management can be implemented through various approaches. Supply chain coordination, which aims to coordinate each stakeholder's actions in the supply chain to achieve the maximized profit of the whole supply chain, is an efficient tool to implement supply chain management (Xu and Beamon, 2006; Basnet and Seuring, 2016). Using examples is a good approach for students to learn supply chain management in the classroom (Munson, 2013). Example is a commonly used pedagogical methodology to motivate students learning, enrich classroom discussions, and facilitate students' in-depth understanding in supply chain management education and research (Nilson, 2010; Pettersson and Segerstedt, 2013; Helms et al., 2016).

Quantitative examples, which show students the profit increase of the supply chain by coordination, can help students understand supply chain coordination benefits more intuitively and visually compared with qualitative examples. Students can then learn the important role of supply chain coordination in building buyer-supplier relationships and long-term partnerships between stakeholders (Jap, 1999). Implications of influential factors of coordination effect and coordination implementation approaches can also be discussed from the examples.

Not many existing quantitative examples of supply chain coordination are appropriate for undergraduate students who are the first-time learners of the supply chain subject due to the complicity and relatively long length of the examples. The contributions of this study lie in the fact that each example in this study illustrates a certain supply chain with featured perspective, shown by the various profit functions, to help students view the mechanism of supply chain coordination through various aspects. Each example has an appropriate length and it is within classroom time to show students the background, models, and numerical examples. These examples provide students a clear view of the benefits of supply chain coordination and its implementation. These examples serve as supplements of an introductory operations management/supply chain management course when the fundamentals of supply chain management are taught. They offer a unique viewpoint for instructors teaching operations management/supply chain management related courses, and provide a snapshot of the mechanism of supply chain coordination.

This study provides six examples, which contain three examples of horizontal coordination and three examples of 

Operations and Supply Chain Management 9(2) pp 131- 147 (C) 2016

vertical coordination, to show the benefits of supply chain coordination in terms of supply chain profit increase. Horizontal coordination happens between the stakeholders who are in the same level of the supply chain (e.g., between retailers), and vertical coordination happens between the stakeholders who are in the different level of the supply chain (e.g., between retailer and supplier). Students know that business objective is to maximize its own profit. However, through these examples, they can know through supply chain coordination with the objective of maximizing the profit of whole supply chain instead of individual companies, all of the stakeholders in the supply chain can be benefited.

According to the different products sold in a specific industry, each supply chain has its own feature. Each example in this study describes a supply chain from a unique perspective in terms of the demand function, various cost functions, and decision variables. Thus, students can find out benefits of coordinated supply chain (also known as integrated or centralized supply chain) is significant in each example, they can also understand the various mechanisms of supply chain coordination implementation.

In each example, after illustrating the model, we provide the analytical results of the stakeholder's optimal actions to compare the corresponding profits of the supply chain with and without coordination. Numerical example is provided to show students the benefits of supply chain coordination intuitively. Sensitivity analysis is shown by graph to show the effect of parameter change on supply chain coordination benefits visually.

The rest of this study is organized as follows. Section two discusses the theoretical foundations and reviews the related literature. Section three introduces three examples of horizontal coordination of supply chains including advertising promoted supply chain, closed-loop supply chain, and supply chain with past-related demand. Section four introduces three examples of vertical coordination of supply chains including price-sensitive supply chain, supply chain with returns, and supply chain with lead-time sensitive demand. Conclusions and classroom implementation are discussed in section five.

\section{THEORETICAL FOUNDATIONS}

\section{AND LITERATURE REVIEW}

Supply chain management can be defined an integrated system that brings the supply base, the companies, and its customers together (Melnyk, et al., 2009; Msimangira and Venkatraman, 2014). Due to the feature of integration, the essence of supply chain management includes coordination (Xu and Beamon, 2006). Therefore, the implementation of supply chain coordination, which can be also described as supply chain integration and supply chain collaboration (Chatzoudes and Chatzoglou, 2011), is a direct approach to achieve the objectives of supply chain management.
However, managing supply chain today faces many challenges. Due to the private information (Shin and Tunca, 2010) and the incentive of maximizing its own profits through deviating its actions from the optimal decisions from the whole supply chain perspective (Heese and Kemahlığlu-Ziya, 2016), many supply chains today haven't obtained the expected competitiveness (Xu and Gursoy, 2015). The actions of each stakeholder in the supply chain are dependent, and thus the non-optimal decision made from one stakeholder triggers a series of non-optimal decision of other stakeholders. This amplifies the inefficiency of whole supply chain.

Supply chain coordination is a strategic response to the challenges of interdependence between stakeholders in supply chain management (Xu and Beamon, 2006). Supply chain coordination can resolve the misalignment of each stakeholder's incentive through motivating all of the parties make actions jointly according to the centralized decision (Shin and Tunca, 2010). The objective of the centralized decision is to maximize the benefits of the whole supply chain. Contracting is among the efficient ways to ensure and stimulate supply chain coordination implementation (Cachon and Lariviere, 2005; Nandi, 2016). Supply chain coordination happens through horizontal coordination between the same levels of stakeholders and/or vertical coordination between different levels of stakeholders. The typical approaches for horizontal coordination include revenue sharing through centralized warehousing (Eppen, 1979), market segmentation (Munson et al., 2003; Munson et al., 2013), and alliance and partnership (Cetiner and Kimms, 2013); and for vertical coordination include channel integration (Yan, 2011), new channel creation (Cai, 2010), and so on.

Students in the operations management or supply chain management-related courses are taught the importance of supply chain management and coordination conceptually. However, due to the complex of supply chain coordination mechanism (Xu and Beamon, 2006), it is worth thinking the approach to let students understand the benefits of supply chain coordination intuitionally. Experiential learning employing examples, cases and software are beneficial for students to understand supply chain management issues and afford them an important differentiator in the job market (Sweeney et al., 2010). This study contributes to the existing studies of using examples to teach supply chain coordination (e.g., Munson et al., 2003) by providing more examples from various supply chain coordination perspectives. In detail, more supply chains with unique features that influence demand (i.e., supply chains with certain-factor sensitive demands) are explored. In addition, more decision variables such as quality efforts and lead times are added and discussed. Furthermore, more mechanisms of supply chain coordination such as profit redistribution and closed-loop are proposed. These examples provide students a more comprehensive view of supply chain coordination and serve as supplements that facilitate students learning in introductory operations management/supply chain management courses. In each 
$\mathrm{Xu}$ : Teaching the Mechanism of Horizontal and Vertical Supply Chain Coordination

Operations and Supply Chain Management 9(2) pp 131- 147 () 2016

quantitative example in this study, we provide a clue for experiential simulation to help students find the influential factors of the supply chain coordination effect. They provide students in-depth knowledge of supply chain management and enhance their education by obtaining relevant experiential exposure to simplified real-business problems (Zeng and Johnson, 2009). These examples can offer students hand-on learning experience through application of software, which is a useful tool to cover more material in less time and makes an efficient and effective learning experience in supply chain management discipline (Adams, 2005).

\section{HORIZONTAL COORDINATION OF}

\section{SUPPLY CHAIN}

\subsection{Example 1: Advertising Promoted Supply Chain}

Advertising is an efficient weapon to make sales efforts to promote more demands in the market today (Dave and Saffer, 2012). Retailers need to decide the optimal advertising costs considering the tradeoff of generated demand and advertising cost.

In this example, two retailers sell two substitute products on the market. The sale can be generated more by advertising. The primary demand for the market of the two products is $D$. With advertising cost $k$, the demand can be increased to $D a k^{b}$, where $a$ and $b$ are the positive coefficient showing the advertising effect on demand (Xie and Wei, 2009). The marginal advertising effect on demand is usually decreasing, and thus $0<b<1$ (Xie and Wei, 2009). The sale price of the products is $p$ and the marginal cost of the products is $c$. Now the two retailers can choose whether to sell the two products jointly and make the advertising jointly, or each sell one product and make the corresponding individual advertising. This model can be used for multiple sellers who sell multiple substitute products, and all of the products share the certain market demand. Students can compare the profit each retailer obtains under these two cases.

Case 1: Two retailers sell the two products jointly and make the advertising jointly

The two retailers share the whole market demand $D$ and the objective is to maximize their profits. The profit function of the two retailers is as follows:

$$
\pi_{1}+\pi_{2}=(p-c) D a k^{b}-k
$$

The optimal advertising efforts for the two retailers are $k^{*}=\left(\frac{1}{(p-c) D a b}\right)^{\frac{1}{b-1}}$. And the total profit of the two retailers

is $\frac{1}{b}-\left(\frac{1}{(p-c) D a b}\right)^{\frac{1}{b-1}}$. When each of the retailer share their total profits equally, then retailer 1 and retailer 2 each obtains the profit of $\frac{1}{2 b}-\frac{1}{2}\left(\frac{1}{(p-c) D a b}\right)^{\frac{1}{b-1}}$ by making advertising efforts $\frac{1}{2}\left(\frac{1}{(p-c) D a b}\right)^{\frac{1}{b-1}}$.

Case 2: Each retailer sells one product and makes individual advertising

We assume the primary demand for the two substitute products is the same. In other words, each retailer sells one product that has the primary demand of $0.5 D$. Then for each retailer $i(i=1,2)$, it wants to maximize its own profit. The profit function of each retailer is as follows:

$$
\pi_{i}=(p-c) \frac{1}{2} D a k_{i}^{b}-k_{i}
$$

The optimal advertising effort for retailer $i$ is $k_{i}^{*}=\left(\frac{1}{2(p-c) D a b}\right)^{\frac{1}{b-1}}$. And the profit of the each retailer is $\frac{1}{2 b}-\left(\frac{2}{(p-c) D a b}\right)^{\frac{1}{b-1}}$. Thus, the total profit of two retailers is $\frac{1}{b}-2\left(\frac{2}{(p-c) D a b}\right)^{\frac{1}{b-1}}$. Therefore, by coordinating the supply chain through letting each retailer sell its own products and making the corresponding advertising, each retailer needs to make $\left(\frac{1}{2}^{\frac{1}{b-1}}-\frac{1}{2}\right)\left(\frac{1}{(p-c) D a b}\right)^{\frac{1}{b-1}}$ more advertising cost. This results in $\left(\frac{1}{2}-2^{\frac{1}{b-1}}\right)\left(\frac{1}{(p-c) D a b}\right)^{\frac{1}{b-1}}$ more profits for each retailer. Therefore, the whole supply chain containing two retailers wins for $2\left(\frac{1}{2}-2^{\frac{1}{b-1}}\right)\left(\frac{1}{(p-c) D a b}\right)^{\frac{1}{b-1}}$ extra profits. Proof details for Example 1 can be found in Appendix A.1. Students can find out the coordination benefits of 
advertising promoted supply chain through the following numerical example. We set the coefficients as follows: $D=100$, $p=10, \quad c=8, a=1, b=0.5$. Then the whole coordinated advertising promoted supply chain can win for $\$ 5000$ extra profit through each retailer obtaining $\$ 2500$ extra profit. Figure 1 shows the extra profits the supply chain obtains with respect to the advertising effect coefficient $b$. The advertising effect coefficient $b$ shows the extent of the advertising effect on demand. The higher value of $b$ shows the company's unit advertising expense can attract more customer demand because of the possible reasons including appropriate advertising strategy and high-quality product (Milgrom and Roberts, 1986; Mooij and Hofstede, 2010). The value of $b$ typically is a number between 0 and 1 (Xie and Wei, 2009), showing the marginal advertising effect on demand is usually decreasing. That is, although more advertising actions and costs can attract more customers, the marginal effect of the unit advertising cost on attracting customer demand becomes less. The possible reason is most of the targeted customers have already been reached by the certain level of advertising actions, and the increasing advertising efforts can not generate enough new customer demand or significantly expand the market share of the product. This phenomenon is consistent with the theory of diminishing marginal utility (Chateauneuf and Cohen, 1994). From Figure 1, we can find with the increased $b$, the coordination effect to obtain the extra profit for the whole supply chain increases. In addition, the convex curve shows the marginal effect increases.

Thus, coordinating the advertising promoted supply chain through letting each retailer sell its own products and make the corresponding advertising can propose a win-win situation for both of the two retailers. The implementation of this coordination is motivated by each retailer due to the win-win situation.

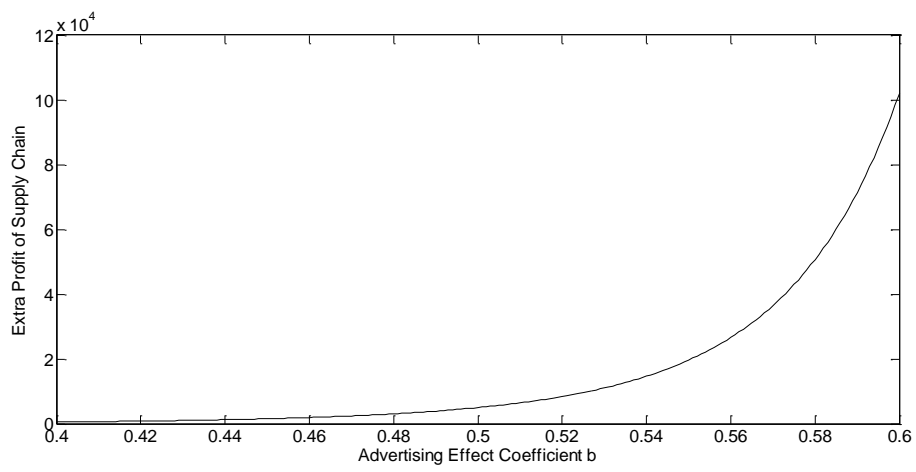

Figure 1 The Effect of Advertising Effect Coefficient b on Extra Profit of Supply Chain

\subsection{Example 2: Closed-loop Supply Chain}

A closed-loop supply chain can be defined as the extension of the normal forward supply chain by including reverse supply chain channels for product return, recycling, remanufacturing, remarketing, and resale (Gan et al., 2014; He, 2015). This example shows the effect of horizontal
Operations and Supply Chain Management 9(2) pp 131- 147 (C) 2016

coordination between retailers by selling
retailer-remanufactured/refurbished products in the supply chain.

We model the product with new condition has the demand $Q=a-b p$, where $D$ is the annual demand, $p$ is the retail price, $a$ is the primary demand coefficient, and $b$ is the price-elasticity coefficient. It shows the linear negative relationship between the retail price and demand (Huang et al., 2010). The wholesale price offered by the supplier is $c$ dollars per unit. Assume $\phi(0<\phi<1)$ is the percentage of products that customers return to retailer after purchase due to various reasons, which is the fact consistent with the return policy of many traditional brick-and-mortar stores and online shopping (Pang et al., 2015). Without loss of generality, we assume customers pay the return delivery fee $s$ to the retailers, and retailers pay the return delivery fee $r$ to suppliers. This shows the reverse logistics process in the reverse supply chain (Chandiran, 2014). Retailer needs to make the decision of the retail price $p$ of the product. Depending on whether the supply chain is closed-loop or not, two cases are discussed.

\section{Case 1: Forward Supply Chain without Coordination}

When the retailer only sells the product with new condition and returns the products to suppliers when customers return the products, the profit of the retailer is:

$\pi_{r}=(1-\phi)\left(a-b p_{1}\right)\left(p_{1}-c\right)-\phi\left(a-b p_{1}\right) r$

The optimal pricing strategy for retailer is $p_{1}^{*}=\frac{a-a \phi+c b-c b \phi+\phi b r}{2 b(1-\phi)}$, and the corresponding profit for the retailer is $(1-\phi)\left(p_{1}^{*}-c\right)\left(a-b p_{1}^{*}\right)-\phi\left(a-b p_{1}^{*}\right) r$.

Case 2: Closed-loop supply chain with selling retailer-remanufactured / refurbished products

This model reflects the closed-loop supply chain characteristics. It can be used for supply chain with reverse logistics due to customer returns, and with customer demand for retailer-remanufactured/refurbished products. In this case, instead of returning products to suppliers for remanufacturing, assume that the retailer can remanufacture/refurbish the product by inspecting, cleaning, and repairing to full working order to assure the product is in an excellent condition. The product may or may not be in original packing. These retailer-remanufactured/refurbished products are different from manufacturer-remanufactured/refurbished products, which are professionally restored to working order by a manufacturer or manufacturer-approved vendor. However, both products, either remanufactured/refurbished by retailers or manufacturers, are popular in the market in some certain industries such as electronics (Neto et al., 2016). We assume the retailer has the capability to remanufacture/refurbish the 
$\mathrm{Xu}$ : Teaching the Mechanism of Horizontal and Vertical Supply Chain Coordination

Operations and Supply Chain Management 9(2) pp 131- 147 (C) 2016

product or coordinate another retailer to remanufacture/refurbish the product. The retailer itself, or the coordinated another retailer sell the remanufacture/refurbish the product. Typically, the retailer-remanufactured/refurbished product's retail price is lower than the new product, which can be denoted as $k p$, where $0<k<1$ (Pang et al., 2015). The cost for retailer to remanufacture / refurbish products is $m$.

In this way, the profit of the retailer/coordinated retailer

is: $\quad \pi_{r}{ }^{\prime}=(1-\phi)\left(a-b p_{2}\right)\left(p_{2}-c\right)+\phi\left(a-b p_{2}\right)\left(k p_{2}-(c+m)\right)$
The optimal pricing strategy for retailer is $p_{2} *=\frac{a-a \phi+c b+\phi b m+a \phi k}{2 b(1-\phi+\phi k)}$. Therefore, by remanufacturing / refurbishing products with the unit cost $m$, the retailer / coordinated retailer can save the reverse logistics fee $r$ to suppliers, and earn the customer demand for remanufactured/refurbished products. This results in extra profit through closed-loop supply chain:

$$
(1-\phi)\left(a-b p_{2}^{*}\right)\left(p_{2}^{*}-c\right)+\phi\left(a-b p_{2}^{*}\right)\left(k p_{2}^{*}-(c+m)\right)-(1-\phi)\left(a-b p_{1}^{*}\right)\left(p_{1}^{*}-c\right)+\phi\left(a-b p_{1}^{*}\right) r
$$

Proof details can be found in Appendix A.2.

Students can know from this example that due to the increased total profit, this is a win-win situation for the retailer selling new products and selling remanufactured / refurbished products. We use the following numerical example to show the closed-loop supply chain coordination effect. Input parameters are as follows: $a=1000, b=1, c=30$, $r=5, m=5, k=0.9$, and $\phi=0.12$. The retail price of the new product $\left(p_{1}^{*}=515.3\right.$ and $\left.p_{2}^{*}=515.5\right)$ is similar in both of the forward supply chain and closed-loop supply chain. However, in closed-loop supply chain with coordination, the retailer/coordinated retailers can obtain $12.08 \%$ extra profit (from $2.07 \times 10^{5}$ to $2.32 \times 10^{5}$ ) from selling remanufactured products.

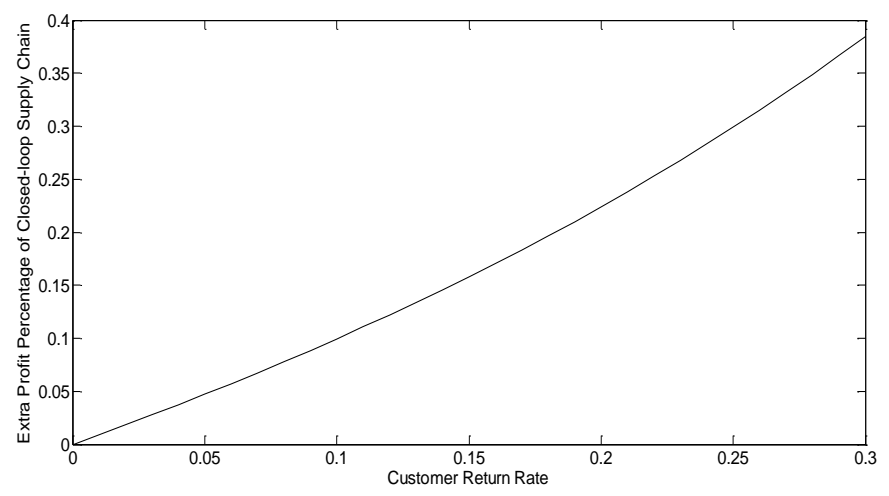

Figure 2 The Effect of Customer Return Rate $\phi$ on the Closed-loop Coordination Effect

Figure 2 shows the effect of customer return rate $\phi$ on the closed-loop coordination effect in terms of the extra profit percentage of closed-loop supply chain. The customer return rate $\phi$ means the percentage of products that customers return to retailer after purchase due to various reasons. Students can see that the relationship between customer return rate and the closed-loop coordination effect is positive. And the marginal effect increases. Customer return rate is influenced by many factors such as the quality of product, the type of product, and sales channels (Jiang and Rosenbloom, 2005; Rao et al., 2014). In this example, we assume the higher customer return rate in Figure 2 is mainly influenced by the type of product or sales channels given the assumption that customer return rate doesn't influence the future customer demand of the product. For example, empirical studies prove that the electronics products and the online sales channels have a higher customer return rate (Subranmanian and Subramanyam, 2012; Neto et al., 2016). The higher return rate opens more opportunities for retailers/coordinated retailers in the closed-loop supply chain to remanufacture/refurbish the products and to sell the remanufactured/refurbished products to customers (Pang et al., 2015). Therefore, the closed-loop supply chain with selling retailer-remanufactured/refurbished products has a higher coordination effects in terms of the extra profit percentage of the closed-loop supply chain compared with forward supply chain without coordination.

\subsection{Example 3: Supply Chain with Past-related Demand}

The customer demand for products comes from two sources: existing customers and new customers (Breuer and Brettel, 2012; Dagger and Danaher, 2014). Some certain industries such as hotel and lodging industry, the proportion of existing customers is significant due to customer loyalty (Hart et al., 1990). Because of this reason, the current period of demand is related to past periods of demand. This phenomenon can be modeled using time series models (Bandyopadhyay and Bhattacharya, 2013).

We use AR(1) model (Ya, 2015) in this example to show the past-related demand. Suppose there are two products $(i=1$, $2)$ to be sold and there are two retailer $(j=1,2)$ in the supply chain. For product $i$, the demand function is: $D_{t i}=h_{i}+k_{i} D_{(t-1) i}+a_{t(i)}$, 
where $h_{i}$ shows the new customer demand in each period, $k_{i}$ is the past-related demand factor $\left(0<k_{i}<1\right)$ showing $k_{i} D_{(t-1) i}$ customers from last period would like to continue buying the product $i$ this period, and $a_{t(i)}$ is a white noise showing the random factor of the demand in each period. Without loss of generality, we consider each period as a month. The expected value of the demand for product $i$ is $\frac{h_{i}}{1-k_{i}}$.

Now the issue for students to consider is in the supply chain with past-related demand, how to coordinate the supply chain horizontally. In detail, the question is whether the two retailers should sell each product separately or sell both products jointly to maximize the profit of the whole supply chain. This model can be used for multiple retailers who sell multiple products. The products' demand is past related due to the possible reasons such as word of mouth effect and frequently revisited buyers (Hart et al., 1990; Cantallops and Salvi, 2014). Proposition 1 provides the mechanism of horizontal coordination in the supply chain with past-related demand.

Proposition 1: When $k_{2}>k_{1}$ and $h_{1}-h_{2}>h_{1} k_{2}-h_{2} k_{1}$, or $k_{2}<k_{1}$ and $h_{1}-h_{2}<h_{1} k_{2}-h_{2} k_{1}$, selling both products jointly can obtain more demands for supply chain than selling each product separately. Otherwise, the supply chain can obtain more demands from each retailer selling each product separately.

\section{Proof: See Appendix A.3.}

The profit of each retailer is positively related to its demand. Proposition 2 shows the horizontal coordination in the supply chain with past-related demand is not a win-win situation.

Proposition 2: Regardless of the mechanism of the horizontal supply chain coordination in the supply chain with past-related demand, the coordination increases one retailer's demand, while decreases the other retailer's demand compared with no coordination.

Proof: See Appendix A.3.

From Proposition 2, students should know only by redistributing the profits from the extra profits one retailer obtains to the other retailer who loses profits due to the supply chain coordination, the later retailer has the motivation to coordinate the supply chain. The amount of profits redistribution should be no less than the profit loss of the retailer because of supply chain coordination.

In summary, when the retailers are coordinated in the supply chain, the whole supply chain can obtain the extra demand of $\left|\frac{h_{1}+h_{2}}{1-\frac{1}{2}\left(k_{1}+k_{2}\right)}-\left(\frac{h_{1}}{1-k_{1}}+\frac{h_{2}}{1-k_{2}}\right)\right|$, and therefore the

profits of the whole supply chain increase. We use the following numerical example to show the supply chain coordination effect. Input parameters are as follows: $h_{l}=300$, $h_{2}=50, k_{l}=0.4$, and $k_{2}=0.6$. Since in this numerical example, $k_{2}>k_{1}$ and $h_{1}-h_{2}>h_{1} k_{2}-h_{2} k_{1}$, selling both products jointly can obtain more profits for supply chain.

By supply chain coordination through the two retailers selling both products jointly, the whole supply chain can obtain $12.00 \%$ extra demand (from 625 to 700). Using this example, students can find out the coordination effect is significant. However, through supply chain coordination, retailer 1 loses 150 demand, although retailer 2 obtains 225 more demand. Thus, only by redistributing the extra profits from retailer 2 to retailer 1 to outweigh the retailer 1 's profit loss, retailer 1 retailer has the motivation to coordinate the supply chain. In this way, the whole supply chain is still benefited by having more demands and profits. Figure 3 shows the effect of retailer 1's past-related demand coefficient $k_{l}$ on the extra profit proportion of supply chain due to coordination. Students can find that when the gap between $k_{l}$ and $k_{2}$ gets greater ( $k_{1}$ gets smaller in this example), the coordination effect is more significant in terms of the increased profit proportion of the supply chain. And the marginal effect decreases.

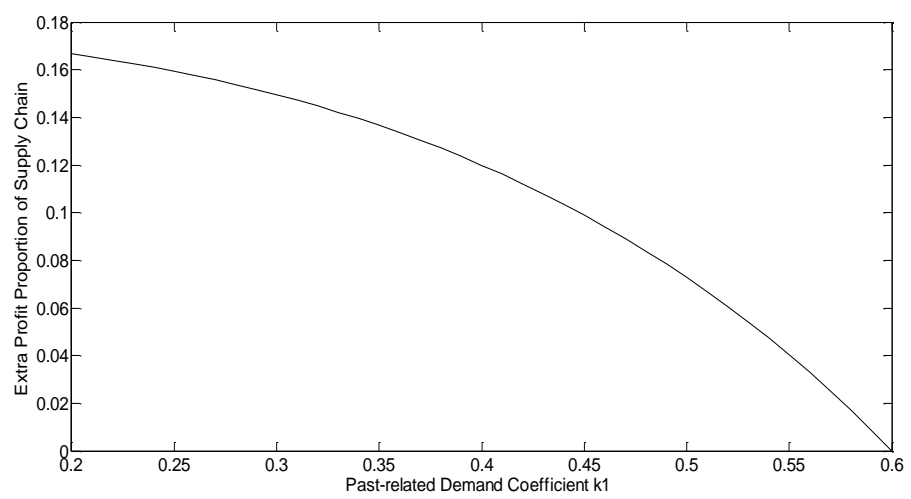

Figure 3 Effect of Retailer 1's Past-related Demand Coefficient $\mathrm{k}_{1}$ on the Extra Profit Proportion of Supply Chain

\section{VERTICAL COORDINATION OF}

\section{SUPPLY CHAIN}

\subsection{Example 1: Price-Sensitive Supply Chain}

Pricing is usually an influential factor of demand. Linear 
$\mathrm{Xu}$ : Teaching the Mechanism of Horizontal and Vertical Supply Chain Coordination

Operations and Supply Chain Management 9(2) pp 131- 147 (C) 2016

negative relationship model between price and demand is used in many studies (e.g., Huang et al., 2010). We assume there are one supplier and one retailer in the supply chain. The demand function for the retailer is: $D=a-b p$, where $D$ is the annual demand, $p$ is the retail price, $a$ is the primary demand coefficient, and $b$ is the price- elasticity coefficient. The retailer needs to decide the retail price $p$ to maximize its profit. The costs includes purchasing cost $w D$, where $w$ is the unit wholesale price offered by the supplier; ordering cost $\frac{D}{Q} S$, where $Q$ is the retailer's order quantity and $S$ is the ordering cost per order; and inventory holding $\operatorname{cost} \frac{Q}{2} h$. The marginal manufacturing cost of the product is denoted by $c$. The profit of the retailer is $\pi_{r}=D(p-w)-\frac{D}{Q} S+\frac{Q}{2} h$, and the profit of the supplier is $\pi_{s}=D(w-c)$.

This model can be used for supply chains with the ordering cost and inventory holding costs, and with price-sensitive demand of the products such as hedonic products (e.g., cosmetics, toys, and jewelry), which are bought by customers mainly for the reasons of playfulness of the shopping experience and sensation obtained from using the products (Okada, 2005). According to whether the supply chain is vertical coordinated or not, we have the following two cases.

\section{Case 1: The supplier and the retailer don't coordinate}

Without coordination, the retailer would like to maximize its own profit. That is, $\operatorname{Max} \pi_{r}=\left(a-b p_{1}\right)\left(p_{1}-w\right)-\frac{D}{Q} S-\frac{Q}{2} h$.

Differences exist between historical academic focus and practical applications in supply chain management (Munson and Jackson, 2015). In practice, because the demand is usually not uniform, instead of Economic order Quantity (EOQ), many retailers use period-order quantity (POQ), which orders the amount of products that cover the demand for the next certain periods of time (Arnold et al., 2012). That is, a proportion of the annual demand is ordered each time (e.g., order the number of products to meet the demand for five weeks) in practice (Chaneski, 2004). Thus, $Q=k D$, where $0<k \leq 1$ (Chaneski, 2004).

In this way, the optimal pricing strategy for retailer is to set $p_{1}^{*}=\frac{2 a+2 b w+k h b}{4 b}$ and the profit of the whole supply chain is $\pi_{S C}=\left(a-b p_{1}{ }^{*}\right)\left(p_{1} *-c\right)-\frac{1}{k} S-\frac{k\left(a-b p_{1}^{*}\right)}{2} h$.

\section{Case 2: The supplier and the retailer coordinate}

With coordination, the retailer would like to maximize the profit of the whole supply chain. That is, $\operatorname{Max} \pi_{S C}=\left(a-b p_{2}\right)\left(p_{2}-w\right)-\frac{D}{Q} S-\frac{Q}{2} h+\left(a-b p_{2}\right)(w-c)$

In this way, the optimal pricing strategy for retailer is to set $p_{2} *=\frac{2 a+2 b c+k h b}{4 b}$ and the profit of the whole supply chain is $\pi_{S C}=\left(a-b p_{2}{ }^{*}\right)\left(p_{2} *-c\right)-\frac{1}{k} S-\frac{k\left(a-b p_{2} *\right)}{2} h$.

Students can learn the terminology of global optimization and local optimization using this example. When retailer maximizes its own profit, the optimal pricing strategy the retailer obtains is based on local optimal solution of the retailer's own profit function. However, this local optimal solution cannot maximize the profit of the whole supply chain, which includes the profit of both of the supplier and the retailer. Only the global optimal solution, which is obtained by maximizing the profit of the whole supply chain, can optimize the profit of the whole supply chain.

When the supply chain is coordinated to maximize the profit of the whole supply chain, the retailer reduces its retail price by $\frac{w-c}{2}$. In this way, the demand of the whole supply chain increases by $a-\frac{b(w-c)}{2}$, and therefore the profit of the whole supply chain increases by $\left(\left(a-b p_{2}^{*}\right)\left(p_{2}^{*}-c\right)-\frac{k\left(a-b p_{2}^{*}\right)}{2} h\right)-\left(\left(a-b p_{1}^{*}\right)\left(p_{1}^{*}-c\right)-\frac{k\left(a-b p_{1}^{*}\right)}{2} h\right)$.

Proof details can be found in Appendix A.4.

However, students should know this is not a win-win situation because although the decreased retail price increases the demand, the profit of the retailer deceases due to the decreased marginal profit. In other words, the increased profit of the whole supply chain comes from the increased profit of the supplier with the profit sacrifice from the retailer. Thus, only by redistributing the profit from the extra profits the supplier obtains due to the supply chain coordination to the retailer, the retailer has the motivation to coordinate the supply chain. The amount of profit redistribution should be no less than the profit loss of retailer because of supply chain coordination.

We use the following numerical example to show the supply chain coordination effect. Input parameters are as follows: $a=1000, b=5, w=100, k=0.2, c=50, h=1$, and $S=20$. Figure 4 shows the retailer's optimal pricing strategy under 
two cases. We can see that when coordinating the supply chain, the retailer needs to decrease its retail price by $17 \%$ (from $\$ 150$ to $\$ 125$ ). In this way, the whole supply chain can obtain $12.57 \%$ extra profits (from $2.4863 \times 10^{4}$ to $2.7988 \times 10^{4}$ ). Using this example, students can find out the coordination effect is significant. However, through supply chain coordination, the retailer loses $3.125 \times 10^{3}$ dollars (from $1.2375 \times 10^{4}$ to $9.25 \times 10^{3}$ ). Thus, only by redistributing $3.125 \times 10^{3}$ dollars from the supplier to the retailer, the retailer has the motivation to coordinate the supply chain.

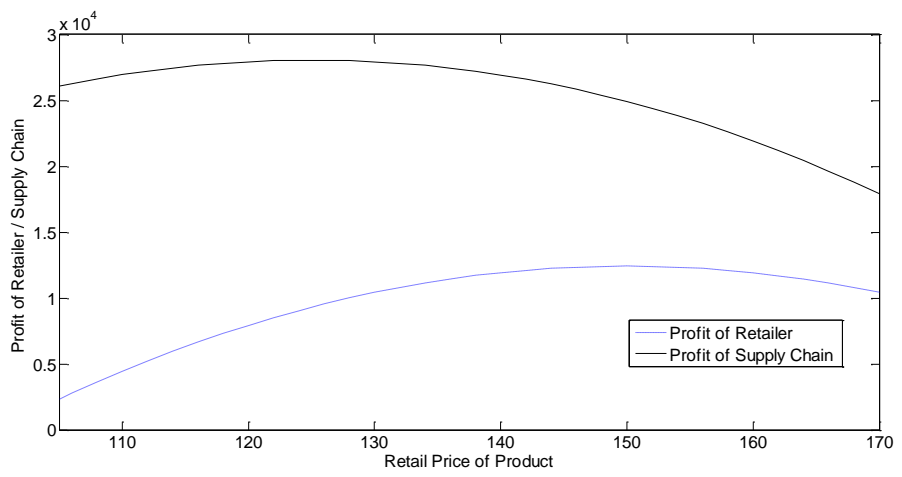

Figure 4 The Effect of Product's Retail Price on the Profit of Retailer and Supply Chain

\subsection{Example 2: Supply Chain with Returns}

Reverse logistics in supply chain due to the return of products is attracting increasing attention from researchers and practitioners today (Liu et al., 2014). The most common reason for products returns is because of manufacturing defects (Giri and Sharma, 2015). Thus, the return rate is quality dependent (Giri and Sharma, 2015).

This example considers supply chain with returns. If the product is defect, customer will return the product to retailer with cost $r$ paid by the retailer, and the retailer will return the product to the supplier with the cost $s$ paid by the supplier. The return costs can come from the reverse logistics costs such as transportation and delivery, and the cost of loss of good will ( $\mathrm{Xu}$ and $\mathrm{Li}, 2016)$. Customers have the probability $\delta_{r}$ to choose another retailer to purchase products when Operations and Supply Chain Management 9(2) pp 131- 147 (C) 2016 products failure happens, and retailer has the probability of $\delta_{s}$ to choose another supplier to purchase products when products failure happens. We assume with the manufacturing quality efforts of $x$, the unit manufacturing cost of the product is $c=a+b x$, where $a$ is the primary manufacturing cost of the product, and $b$ is the sensitive coefficient of the effect of quality efforts on manufacturing cost. The probability of defects is $g=d-e x$, where $d$ is the basic probability of defect, and $e$ is the sensitive coefficient of the effect of quality efforts on reducing the defects. With the annual demand $D$, the products failure cost for supplier is $g D\left(\delta_{s}(w-c)+s\right)$, the manufacturing failure cost for retailer is $g D\left(\delta_{r}(p-w)+r\right)$, where $p$ is the retailer price offered by the retailer and $w$ is the wholesale price offered by supplier. Thus, the supplier's profit is $(w-c) D-g D\left(\delta_{s}(w-c)+s\right)$ and the retailer's profit is $(p-w) D-g D\left(\delta_{r}(p-w)+r\right)$. This model can be used in supply chains with defective products and the corresponding customer returns because of the defective products. According to whether the supply chain is vertical coordinated or not, we have the following two cases.

Case 1: The supplier and the retailer don't coordinate

Without coordination, the supplier would like to maximize its own profit. That is, $\operatorname{Max} \pi_{s}=(w-c) D-g D\left(\delta_{s}(w-c)+s\right)$.

In this way, the optimal manufacturing quality efforts made by the supplier is $x_{1}^{*}=\frac{-b+\delta_{s} e w-\delta_{s} e a+\delta_{s} d b+s e}{2 \delta_{s} e b}$ and the profit of the whole supply chain is:

$$
\pi_{S C}=\left(w-\left(a+b x_{1}^{*}\right)\right) D-\left(d-e x_{1}^{*}\right) D\left(\delta_{s}\left(w-\left(a+b x_{1}^{*}\right)\right)+s\right)+(p-w) D-\left(d-e x_{1}^{*}\right) D\left(\delta_{r}(p-w)+r\right)
$$

Case 2: The supplier and the retailer coordinate

With coordination, the retailer would like to maximize the profit of the whole supply chain. That is, Max $\pi_{S C}=(w-c) D-g D\left(\delta_{s}(w-c)+s\right)+(p-w) D-g D\left(\delta_{r}(p-w)+r\right) \quad$ profit of the whole supply chain is: $\pi_{S C}=\left(w-\left(a+b x_{2} *\right)\right) D-\left(c-d x_{2} *\right) D\left(\delta_{s}\left(w-\left(a+b x_{2} *\right)\right)+s\right)+(p-w) D-\left(c-d x_{2}^{*}\right) D\left(\delta_{r}(p-w)+r\right)$.

Following the logic of Example 1 in Section 4, when
In this way, the optimal quality efforts for retailer is $x_{2} *=\frac{-b+\delta_{s} e w-\delta_{s} e a+\delta_{s} d b+s e+e \delta_{r}(p-w)+e r}{2 \delta_{s} e b}$ and the coordinating the supply chain through obtaining the global optimal solution to maximize the profit of the whole supply 
$\mathrm{Xu}$ : Teaching the Mechanism of Horizontal and Vertical Supply Chain Coordination

Operations and Supply Chain Management 9(2) pp 131- 147 (C) 2016

141

chain, the supplier increases its manufacturing quality efforts by $\frac{\delta_{r}(p-w)+r}{2 \delta_{s} b}$. Therefore, due to the reduced product failure cost, the whole supply chain's profit increases by $d D \delta_{s} b\left(x_{2} *^{2}-x_{1} *^{2}\right)+D\left(b-\delta_{s}(c b+d w-d a+d s)-d\left(\delta_{r}(p-w)+r\right)\right)\left(x_{2}^{*}-x_{1} *\right)$

. Proof details can be found in Appendix A.5.

However, students should know this is not a win-win situation because although the increased manufacturing quality efforts reduce product failure cost, the profit of the supplier decreases due to the increased quality efforts. In other words, the increased profit of the whole supply chain comes from the increased profit of the retailer with the profit sacrifice from the supplier. Thus, only by redistributing the profit from the extra profits the retailer obtains due to the supply chain coordination to the supplier, the supplier has the motivation to coordinate the supply chain. The amount of redistribution profit should be no less than the profit loss of supplier because of supply chain coordination.

We use the following numerical example to show the supply chain coordination effect. Input parameters are as follows: $D=1000, w=200, p=300, r=30, s=30, a=50, b=2, d=1$, $e=0.015, \quad \delta_{s}=0.4$, and $\delta_{s}=0.4$.

Figure 5 shows the supplier's optimal manufacturing quality efforts under two cases. We can see that when coordinating the supply chain, the supplier needs to increase its quality efforts by 43.75 dollars. In this way, the whole supply chain can obtain $23.71 \%$ extra profits (from $9.70 \times 10^{4}$ to $1.20 \times 10^{5}$ ). Using this example, students can find out the coordination effect is significant. However, through supply chain coordination, the supplier loses $2.30 \times 10^{4}$ dollars (from $6.05 \times 10^{4}$ to $\left.3.75 \times 10^{3}\right)$. Thus, only by redistributing $2.30 \times 10^{4}$ dollars from the retailer to the supplier, the supplier has the motivation to coordinate the supply chain.

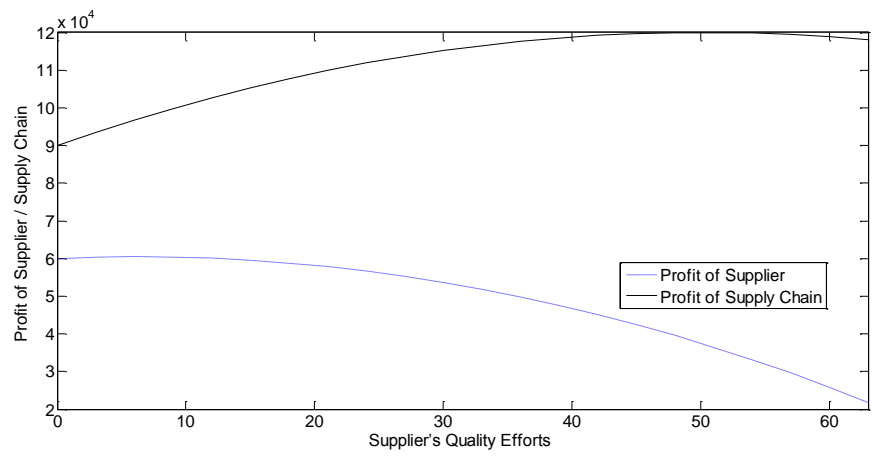

Figure 5 The Effect of Supplier's Manufacturing Quality Efforts on the Profit of Supplier and Supply Chain

\subsection{Example 3: Supply Chain with Lead-time Sensitive Demand}

Supply and order lead times can have significant effects on customer demand due to the reasons of operations performance and perceived customer service (Yang and Geunes, 2007). Many customers prefer shorter lead times. This example considers supply chain with lead-time sensitive demand.

Suppose the supply chain has one supplier and one retailer. The retail price is exogenous, which is decided by the market. The annual demand is lead-time sensitive, which has a negative relationship with the lead time, as shown by $D=a-b L$, where $a$ is the primary demand, and $b$ is the sensitive coefficient of the effect of lead time on demand. With the lead time $L$, the supplier charges the ordering cost from the retailer as $S+g \frac{m}{L}$, where $S$ is the fixed ordering cost, $m$ is the basic ordering cost for certain lead time, and $g$ is the sensitive coefficient of the effect of lead time on ordering cost. The increased ordering cost comes from higher transportation cost, more labor resources utilization, and improved technology due to the shortened lead time. The retail price of the product offered by the retailer is $p$, wholesale price offered by the supplier is $w$, and the unit manufacturing cost is $c$. With the order quantity $Q$, we consider the total cost of the retailer, which include the purchasing cost $w D$, the ordering cost $\frac{D}{Q}\left(S+g \frac{m}{L}\right)$, and inventory holding cost $\frac{Q h}{2}$, where $h$ is the unit inventory holding cost per year. This model can be used in supply chains with lead-time sensitive demand, where less lead time facilitated by faster shipping after order arrives and fast delivery process increases customer demand. Products with lead-time sensitive demand include fashion products and perishable products such as vegetables (Engelseth, 2015). According to whether the supply chain is vertical coordinated or not, we have the following two cases.

\section{Case 1: The supplier and the retailer don't coordinate}

Without coordination, the retailer would like to maximize its own profit. That is, $\operatorname{Max} \pi_{r}=\left(a-b L_{1}\right)(p-w)-\frac{Q}{2} h-\frac{a-b L_{1}}{Q}\left(S+g \frac{m}{L_{1}}\right)$.

Following the logic in Section 4.1, we assume in practice $Q=k D$, where $0<k \leq 1$ (Chaneski, 2004). In this way, the optimal lead time of ordering for retailer to choose is: 


$$
L_{1}^{*}=\frac{\sqrt{2 g m}}{\sqrt{k(2 b p-2 w b-h b k)}} .
$$

\section{Case 2: The supplier and the retailer coordinate}

With coordination, the retailer would like to maximize

the profit of the whole supply chain. That is, $\operatorname{Max} \pi_{S C}=\left(a-b L_{2}\right)(p-w)-\frac{Q}{2} h-\frac{a-b L_{2}}{Q}\left(S+g \frac{m}{L_{2}}\right)+(w-c)\left(a-b L_{2}\right)$.

In this way, the optimal lead time for retailer is $L_{2} *=\frac{\sqrt{2 g m}}{\sqrt{k(2 b p-2 w b-h b k+2 b w-2 b c)}}$. Since $w>c, L_{2} *<L_{1} *$. Therefore, when the supply chain is coordinated, the lead time is reduced

$$
\frac{\sqrt{2 g m}}{\sqrt{k(2 b p-2 w b-h b k})}-\frac{\sqrt{2 g m}}{\sqrt{k(2 b p-2 w b-h b k+2 b w-2 b c})}
$$

Therefore, due to the increased demand, the whole supply chain increases the profit by $\left(L_{1} *-L_{2} *\right) b\left(p-\frac{k h}{2}-c\right)-\frac{g m}{k}\left(\frac{1}{L_{2} *}-\frac{1}{L_{1} *}\right)$. Proof details can be found in Appendix A.6.

However, students should know this is not a win-win situation. The reason is although the reduced lead time increases demand, and thus the profit of whole supply chain increases due to the increased profit of supplier, the profit of retailer decreases due to the increased ordering cost. Thus, only by redistributing the profit from the extra profits the supplier obtains due to the supply chain coordination to the retailer, the retailer has the motivation to coordinate the supply chain by reducing the lead time. The amount of redistribution profit should be no less than the profit loss of retailer because of supply chain coordination.

We use the following numerical example to show the supply chain coordination effect. Input parameters are as follows: $a=300, b=100, w=70, k=0.2, c=20, h=1, m=800$, $p=100, g=1$, and $S=50$. Figure 6 shows the retailer's optimal lead time decision under two cases. Students can see that when coordinating the supply chain, the retailer needs to reduce its lead time by 0.45 days (from 1.16 to 0.71 days). In this way, the whole supply chain can obtain $12.73 \%$ extra profits (from $1.10 \times 10^{4}$ to $1.24 \times 10^{4}$ ). Using this example, students can find out the coordination effect is significant. However, through supply chain coordination, the retailer loses 852 dollars (from 1803 to 951 dollars). Thus, only by redistributing 852 dollars from the supplier to the retailer, the retailer has the motivation to coordinate the supply chain.

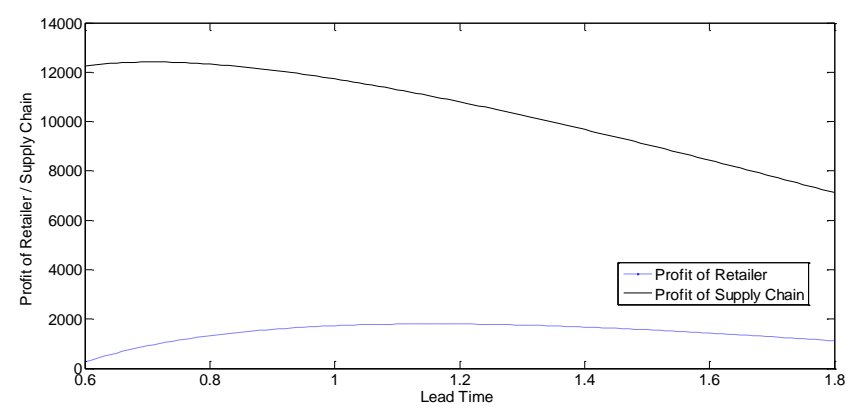

Figure 6 The Effect of Lead Time on the Profit of Retailer and Supply Chain

\section{CONCLUSIONS AND}

\section{IMPLICATIONS}

\subsection{Conclusions}

This study provides six examples of supply chain coordination. Among them, three examples discuss horizontal coordination among retailers, which include advertising promoted supply chain, closed-loop supply chain, and supply chain with past-related demand. Three other examples discuss vertical coordination among retailer and supplier, which include price-sensitive supply chain, supply chain with returns, and supply chain with lead-time sensitive demand. When summarizing the benefits of supply chain coordination, instructors may need to let students think about the following aspects.

First, without coordination, the objective of each stakeholder is to obtain the local optimal solution of the corresponding actions to maximize its own profit. Only by obtaining the global optimal solution of the corresponding actions to maximize the supply chain's profit, the mechanism of supply chain coordination can be achieved.

Second, motivated party in the supply chain coordination may be different depending on whether the coordination can be achieved by a win-win situation. Although the advertising promoted supply chain example in this study proposes a win-win situation, which motivates each retailer to coordinate the supply chain, more often than not, as seen from many other examples, supply chain coordination cannot be achieved by a win-win situation. Thus, extra profits need to be redistributed from the beneficial parties to the sacrificed parties. Only through profit distribution with at least the amount of profit loss due to supply chain coordination, the sacrificed parities have motivation to implement coordination.

Third, in practice, supply chain coordination can be achieved through multiple approaches. Contracting and building the long-term partnerships are among the most efficient methods. Students should know today's competition is among supply chains instead of individual businesses, and thus achieving the maximized profit of the whole supply chain 
$\mathrm{Xu}$ : Teaching the Mechanism of Horizontal and Vertical Supply Chain Coordination

Operations and Supply Chain Management 9(2) pp 131- 147 (C) 2016

through strategic partnerships between various parties in the supply chain is essential. However, the obstacles to implement supply chain coordination cannot be ignored. Possible sources of obstacles come from information asymmetry and selfish motives (Heese and Kemahlığlu-Ziya, 2016). Thus, information sharing using Electronic data interchange (EDI) is one approach to overcome these obstacles. Information sharing can also increase trust between various parities in the supply chain (Talavera, 2014).

Lastly, supply chain coordination can be achieved horizontally and vertically simultaneously. Greater coordination effects can be achieved through more stakeholders being involved. Stakeholders can also utilize various contracts such as revenue sharing contract, buy-back contract, quantity discounts contract, quantity-flexibility contract, franchise contract, and sales-rebate contract to obtain more significant coordination effects.

\subsection{Classroom Implementation and Extensions}

These six examples can be introduced in one class or separately when discussing the benefits of supply chain coordination. Supply chain management theory needs to be introduced ahead of these examples. The numerical example in each of the six examples provides the supply chain coordination effect intuitionally. Spreadsheets and the graph in each example can be used to show the effects of influential factors in the model on the supply chain coordination effects. The mechanism and implementation of supply chain coordination can be discussed in the end.

Future extensions of supply chain coordination examples can be conducted in the following aspects. First, three-level supply chain coordination examples can be included. That is, besides suppliers and retailers, distributors' actions can also be involved in supply chain coordination to maximize the profit of the whole supply chain. Students can then understand the more significant effects of supply chain coordination when multiple-level parties in the supply chain are involved. Second, supply chain coordination examples in some special industries can be introduced. Due to the characteristics of some certain industry (e.g., hospitality, healthcare, sports), it is interesting to discuss the effect of its supply chain coordination, and compare the effect with regular manufacturing supply chain coordination. Lastly, the examples of supply chain coordination through some certain contracts such as revenue sharing contract, buy-back contract, and quantity discount contacts can be introduced to let students understand the effect of certain contracts on supply chain coordination. Comparison between the effect of various contracts such as wholesale contract and revenue sharing contract can provide students a clear idea about the function of various contracts on supply chain coordination.

\section{APPENDICES}

\section{Appendix A.1: Proof of Example 1 in Section 3}

In case 1 , by taking the FOC w.r.t $k$ of the profit function, we $\operatorname{get}(p-c) D a b k^{b-1}-1$. Thus, by taking the SOC w.r.t $k$, we get $(p-c) \operatorname{Dab}(b-1) k^{b-2}<0$. Thus, by setting $\mathrm{FOC}=0$, we get the optimal $k^{*}=\left(\frac{1}{(p-c) D a b}\right)^{\frac{1}{b-1}}$.

In case 2 , by taking the FOC w.r.t $k$ of the profit function, we get $\frac{1}{2}(p-c) D a b k^{b-1}-1$. Thus, by taking the SOC w.r.t $k$, we get $\frac{1}{2}(p-c) D a b(b-1) k^{b-2}<0$. Thus, by setting $\mathrm{FOC}=0$, we get the optimal $k_{i}^{*}=\left(\frac{1}{2(p-c) D a b}\right)^{\frac{1}{b-1}}$.

Thus, for each retailer, by plugging in the optimal advertising costs to the profit function, we can find out the difference between case 2 and case 1 is $\left(\frac{1}{2}-2^{\frac{1}{b-1}}\right)\left(\frac{1}{(p-c) D a b}\right)^{\frac{1}{b-1}}>0$. Thus, the whole supply chain containing two retailers in case 2 has $2\left(\frac{1}{2}-2^{\frac{1}{b-1}}\right)\left(\frac{1}{(p-c) D a b}\right)^{\frac{1}{b-1}}$ more profits than in case 1.

\section{Appendix A.2: Proof of Example 2 in Section 3}

In case 1 , by taking the FOC w.r.t $p$ of the profit function of retailer, we get $(1-\phi)(a-b p)-(1-\phi)(p-c) b+\phi b r$. By taking the SOC w.r.t. $p$ of the profit function of retailer, we get $-2(1-\phi) b<0$.

Thus, by setting $\mathrm{FOC}=0$, we get the optimal $p_{1}^{*}=\frac{a-a \phi+c b-c b \phi+\phi b r}{2 b(1-\phi)}$.

In case 2 , by taking the FOC w.r.t $p$ of the profit function of supply chain, we get $(1-\phi)(a-b p)-(1-\phi)(p-c) b-\phi b(k p-c-m)+\phi(a-b p) k$. By taking the SOC w.r.t. $p$ of the profit function of supply 
chain, we get $-2(1-\phi) b-2 \phi b k<0$.

Thus, by setting $\mathrm{FOC}=0$, we get the optimal $p_{2}^{*}=\frac{a-a \phi+c b+\phi b m+a \phi k}{2 b(1-\phi+\phi k)}$.

The value

$(1-\phi)\left(p_{2} *-c\right)\left(a-b p_{2}^{*}\right)+\phi\left(k p_{2} *-(c+m)\right)\left(a-b p_{2}^{*}\right)-(1-\phi)\left(p_{1}^{*} *-c\right)\left(a-b p_{1}^{*}\right)+\phi\left(a-b p_{1}^{*}\right) r$

is greater than 0 since by definition, $p_{2} *$ is obtained by the signs

is $\frac{1}{2} \frac{h_{1}+h_{2}}{1-\frac{1}{2}\left(k_{1}+k_{2}\right)}-\frac{h_{2}}{1-k_{2}}=-\frac{\left(h_{2}-h_{1}\right)+\left(h_{1} k_{2}-h_{2} k_{1}\right)}{\left(2-\left(k_{1}+k_{2}\right)\right)\left(1-k_{2}\right)}$. Since global optimization, which incurs the maximized function value of the closed-loop supply chain profit.

\section{Appendix A.3: Proof of Example 3 in Section 3}

When the two retailers sell products separately, the expected demand for retailer 1 is $\frac{h_{1}}{1-k_{1}}$ and for retailer 2 is $\frac{h_{2}}{1-k_{2}}$. Thus, the expected demand for the supply chain is $\frac{h_{1}}{1-k_{1}}+\frac{h_{2}}{1-k_{2}}$. When both retailers sell products jointly, the expected demand for the supply chain is $h_{1}+h_{2} \quad$. Thus,

$$
\frac{h_{1}+h_{2}}{1-\frac{1}{2}\left(k_{1}+k_{2}\right)}
$$

$\frac{h_{1}+h_{2}}{1-\frac{1}{2}\left(k_{1}+k_{2}\right)}-\left(\frac{h_{1}}{1-k_{1}}+\frac{h_{2}}{1-k_{2}}\right)=\frac{\frac{1}{2}\left(k_{2}-k_{1}\right)\left(\left(h_{1}-h_{2}\right)+\left(k_{1} h_{2}-k_{2} h_{1}\right)\right)}{\left(1-k_{1}\right)\left(1-k_{2}\right)\left(1-\frac{1}{2}\left(k_{1}+k_{2}\right)\right)}$ Since $0<k_{1}<1$ and $0<k_{2}<1,\left(1-k_{1}\right)\left(1-k_{2}\right)\left(1-\frac{1}{2}\left(k_{1}+k_{2}\right)\right)>0$. Thus, when $k_{2}>k_{1}$ and $h_{1}-h_{2}>h_{1} k_{2}-h_{2} k_{1}$, or $k_{2}<k_{1}$ and $h_{1}-h_{2}<h_{1} k_{2}-h_{2} k_{1}, \frac{h_{1}+h_{2}}{1-\frac{1}{2}\left(k_{1}+k_{2}\right)}-\left(\frac{h_{1}}{1-k_{1}}+\frac{h_{2}}{1-k_{2}}\right)>0$.

When $k_{2}>k_{1} \quad$ and $\quad h_{1}-h_{2}<h_{1} k_{2}-h_{2} k_{1} \quad, \quad$ or $\quad k_{2}<k_{1} \quad$ and $h_{1}-h_{2}>h_{1} k_{2}-h_{2} k_{1}, \frac{h_{1}+h_{2}}{1-\frac{1}{2}\left(k_{1}+k_{2}\right)}-\left(\frac{h_{1}}{1-k_{1}}+\frac{h_{2}}{1-k_{2}}\right)<0$. Therefore, the proposition 1 is proved.

The demand gap between selling both products jointly and selling each product separately for retailer 1 is $\frac{1}{2} \frac{h_{1}+h_{2}}{1-\frac{1}{2}\left(k_{1}+k_{2}\right)}-\frac{h_{1}}{1-k_{1}}=\frac{\left(h_{2}-h_{1}\right)+\left(h_{1} k_{2}-h_{2} k_{1}\right)}{\left(2-\left(k_{1}+k_{2}\right)\right)\left(1-k_{1}\right)}$, and for retailer 2

\section{Appendix A.4: Proof of Example 1 in Section 4}

In case 1, by taking the FOC w.r.t $p$ of the profit function of retailer, we get $a-2 b p_{1}+b w+\frac{1}{2} k h b$. By taking the

$-\frac{\left(h_{2}-h_{1}\right)+\left(h_{1} k_{2}-h_{2} k_{1}\right)}{\left(2-\left(k_{1}+k_{2}\right)\right)\left(1-k_{2}\right)}$ are always opposite. Thus, one retailer obtains more demand due to horizontal supply chain coordination and the other retailer sacrifices. The retailer who is benefited or sacrificed depends on the relationship between $h_{1}-h_{2}$ and $h_{1} k_{2}-h_{2} k_{1}$. Therefore, this horizontal supply chain coordination in the supply chain with past-related demand is not a win-win situation, and thus needs the profit redistribution from the benefited retailer to the sacrificed retailer.

SOC w.r.t. $p$ of the profit function of retailer, we get $-2 b<0$. Thus, by setting $\mathrm{FOC}=0$, we get the optimal $p_{1}^{*}=\frac{2 a+2 b w+k h b}{4 b}$.

In case 2, by taking the FOC w.r.t $p$ of the profit function of supply chain, we get $a-2 b p_{2}+b c+\frac{1}{2} k h b$. By taking the SOC w.r.t. $p$ of the profit function of retailer, we get $-2 b<0$.

Thus, by setting $\mathrm{FOC}=0$, we get the optimal $p_{2}{ }^{*}=\frac{2 a+2 b c+k h b}{4 b}$. The value of $\left(\left(a-b p_{2}^{*}\right)\left(p_{2}^{*}-c\right)-\frac{k\left(a-b p_{2}^{*}\right)}{2} h\right)-\left(\left(a-b p_{1}^{*}\right)\left(p_{1}^{*}-c\right)-\frac{k\left(a-b p_{1}^{*}\right)}{2} h\right)$ is greater than 0 since by definition, $p_{2} *$ is obtained by the global optimization, which incurs the maximized function value of the supply chain profit. 
$\mathrm{Xu}$ : Teaching the Mechanism of Horizontal and Vertical Supply Chain Coordination

Operations and Supply Chain Management 9(2) pp 131- 147 () 2016

\section{Appendix A.5: Proof of Example 2 in Section 4}

In case 1, by taking the FOC w.r.t $x$ of the profit function of supplier,

we

get $-b D+e D\left(\delta_{s}(w-a-b x)+s\right)+(d-e x) D \delta_{s} b$. By taking the SOC w.r.t. $x$ of the profit function of supplier, we get $-2 e D \delta_{s} b<0$.

Thus, by setting $\mathrm{FOC}=0$, we get the optimal

$$
x_{1}^{*}=\frac{-b+\delta_{s} e w-\delta_{s} e a+\delta_{s} d b+s e}{2 \delta_{s} e b} .
$$

In case 2 , by taking the FOC w.r.t $x$ of the profit function of supply chain, we get

$-b D+e D\left(\delta_{s}(w-a-b x)+s\right)+(d-e x) D \delta_{s} b+e D\left(\delta_{r}(p-w)+r\right)$

. By taking the SOC w.r.t. $x$ of the profit function of supply chain, we get $-2 e D \delta_{s} b<0$.

Thus, by setting FOC $=0$, we get the optimal

$$
x_{2}^{*}=\frac{-b+\delta_{s} e w-\delta_{s} e a+\delta_{s} d b+s e+e \delta_{r}(p-w)+e r}{2 \delta_{s} e b} .
$$

The value of $x_{2} *-x_{1}^{*}=\frac{\delta_{r}(p-w)+r}{2 \delta_{s} b}>0$ is greater than 0

$$
L_{1}^{*}=\frac{\sqrt{2 g m}}{\sqrt{k(2 b p-2 w b-h b k)}} .
$$

In case 2 , by taking the FOC w.r.t $L$ of the profit function of supply chain, we get $-b p+b w+\frac{1}{2} h b k+\frac{g m}{k L^{2}}-(w-c) b$. Вy

taking the SOC w.r.t. $L$ of the profit function of supply chain, we get $-\frac{2 m}{k L^{3}}<0$.

Thus, by setting FOC=0, we get the optimal

$$
L_{2} *=\frac{\sqrt{2 g m}}{\sqrt{k(2 b p-2 w b-h b k+2 b w-2 b c})} .
$$

The value of $L_{2} *-L_{1} *<0$ is greater than 0 since $w>c$. The value

$$
\begin{aligned}
& \left(a-b L_{2}^{*}\right)(p-w)-\frac{Q}{2} h-\frac{a-b L_{2} *}{Q}\left(S+g \frac{m}{L_{2} *}\right)+(w-c)\left(a-b L_{2} *\right)-\left(a-b L_{1}^{*}\right)(p-w) \\
& +\frac{Q}{2} h+\frac{a-b L_{1} *}{Q}\left(S+g \frac{m}{L_{1}^{*}}\right)-(w-c)\left(a-b L_{1}^{*}\right)
\end{aligned}
$$

is greater than 0 since by definition, $L_{2} *$ is obtained by the global optimization, which incurs the maximized function value of the supply chain profit.

\section{REFERENCES}

Adams, J., Flatto, J., \& Gardner, L. (2005). Combining hands-on,

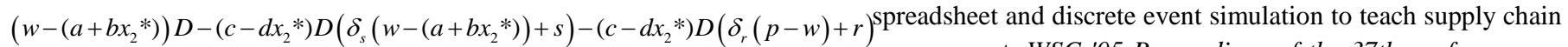
$-\left(w-\left(a+b x_{1}^{*}\right)\right) D+\left(c-d x_{1}^{*}\right) D\left(\delta_{s}\left(w-\left(a+b x_{1}^{*}\right)\right)+s\right)+\left(c-d x_{1}^{*}\right) D(\delta(p-w)+r)$ management. WSC '05 Proceedings of the 37th conference on (w-

is greater than 0 since by definition, $x_{2} *$ is obtained by the

Akalin, G. I., Huang, Z., \& Willems, J. R. (2016). Is Supply Chain Management Replacing Operations Management in the Business Core Curriculum? Operations and Supply Chain Management: An International Journal, 9(2), pp.119-130.

Anderson, E. G., \& Morrice, D. J. (2000). A simulation game for teaching service-oriented supply chain management: does information sharing help managers with service capacity decisions? Production and Operations Management, 9(1), pp.40-55.

Arnold, J. R. T., Chapman, S. N., \& Clive, L. M. (2012). Introduction to Materials Management. Prentice Hall, Upper Saddle River, NJ.

SOC w.r.t. $L$ of the profit function of retailer, we get $-\frac{2 m}{k L^{3}}<0$.

Thus, by setting FOC=0, we get the optimal
Bandyopadhyay, S., \& Bhattacharya, R. (2013). A generalized measure of bullwhip effect in supply chain with ARMA demand process under various replenishment policies. The International Journal of Advanced Manufacturing Technology, 68(5), pp.963-979.

Basnet, C., \& Seuring, S. (2016). Demand-oriented Supply Chain 
Strategies - A Review of the Literature. Operations and Supply Chain Management: An International Journal, 9(2), pp.73-89.

Breuer, R., \& Brettel, M. (2012). Short- and long-term effects of online advertising: Differences between new and existing customers. Journal of Interactive Marketing, 26(3), pp.155-166.

Cachon, G. P., \& Lariviere, M. A. (2005). Supply chain coordination with revenue-sharing contracts: strengths and limitations. Management Science, 51(1), pp.30-44.

Cai, G. (2010). Channel selection and coordination in dual-channel supply chains. Journal of Retailing, 86(1), pp.22-36.

Cantallops, A. S., \& Salvi, F. (2014). New consumer behavior: A review of research on eWOM and hotels. International Journal of Hospitality Management, 36, pp.41-51.

Cetiner, D., \& Kimms, A. (2013). Assessing fairness of selfish revenue sharing mechanisms for airline alliances. Omega, 41(4), pp.641-652.

Chandiran, P. (2014). Optimization of Inventory for Two Level Multiple Retailers-Single Manufacturer Reverse Supply Chain. Operations and Supply Chain Management: An International Journal, 7(1), pp.32-37.

Chaneski, W. (2004). Using a supermarket to regulate your work flow. Available online: http://www.mmsonline.com/columns/using-a-supermarket-to-r egulate-your-work-flow. (Accessed November 20, 2015).

Chateauneuf, A., \& Cohen, M. (1994). Risk seeking with diminishing marginal utility in a non-expected utility model. Journal of Risk and Uncertainty, 9(1), pp.77-91.

Chatzoudes, D., \& Chatzoglou, P. (2011). The Impact of 360o Supply Chain Integration on Operational and Business Performance. Operations and Supply Chain Management: An International Journal, 4(2/3), pp.145-156.

Dagger, T. S., \& Danaher, P. J. (2014). Comparing the effect of store remodeling on new and existing customers. Journal of Marketing, 78(3), pp.62-80.

Dave, D., \& Saffer, H. (2012). Impact of Direct-to-Consumer Advertising on Pharmaceutical Prices and Demand. Southern Economic Journal, 79(1), pp.97-126.

Engelseth, P. (2015). Customer-Responsive Supply of Local Foods. Operations and Supply Chain Management: An International Journal, 8(3), pp.111-119.

Eppen, G. D. (1979). Note: Effects of centralization on expected costs in a multi-location newsboy problem. Management Science, 25(5), pp.498-501.

Gan, S. S., Pujawan, I. N., \& Suparno. (2014). Remanufacturing of Short Life-cycle Products. Operations and Supply Chain Management: An International Journal, 7(1), pp.13-22.

Giri, B. C., \& Sharma, S. (2015). Optimizing a closed-loop supply chain with manufacturing defects and quality dependent return rate. Journal of Manufacturing Systems, 35, 92-111.

Hart, C. W. L., Heskett, J. L., \& Sasser, W. E. (1990). The Profitable Art of Service Recovery, Harvard Business Review, 68(4), pp.148-156.

He, Y. (2015). Acquisition pricing and remanufacturing decisions in a closed-loop supply chain. International Journal of Production
Operations and Supply Chain Management 9(2) pp 131- 147 (C) 2016

Economics, 163, pp.48-60.

Heese, H. S., \& Kemahlıoğlu-Ziya, E. (2016). Don't ask, don't tell: Sharing revenues with a dishonest retailer. European Journal of Operational Research, 248(2), pp.580-592.

Helms, M. M., LeMay, S. A., \& Dwyer, M. J. (2016). World Views and the Evaluation of NGO Supply Chains: Thirteen Cases from Guatemala. Operations and Supply Chain Management: An International Journal, 9(2), pp.90-104.

Huang, G. Q., Song, H., \& Zhang, X. (2010). A comparative analysis of quantity and price competitions in tourism supply chain networks for travel packages. The Service Industries Journal, 30(10), pp.1593-1606.

Jap, S. D. (1999). Pie-expansion efforts: Collaboration processes in buyer-supplier relationships. Journal of Marketing Research, 36(4), pp.461-475.

Jiang, P., \& Rosenbloom, B. (2005). Customer intention to return online: price perception, attribute-level performance, and satisfaction unfolding over time. European Journal of Marketing, 39(1/2), pp.150-174.

Liu, J., Mantin, B., \& Wang, H. (2014). Supply chain coordination with customer returns and refund-dependent demand. International Journal of Production Economics, 148, pp.81-89.

Melnyk, S. A., Lummus, R. R., Vokurka, R. J., Burns, L. J., \& Sandor, J. (2009). Mapping the future of supply chain management: A Delphi Study. International Journal of Production Research, 47, pp.4629-4653.

Milgrom, P., \& Roberts, J. (1986). Price and advertising signals of product quality. The Journal of Political Economy, 94(4), pp.796-821.

Mooij, M. D., \& Hofstede, G. (2010). The Hofstede model: Applications to global branding and advertising strategy and research. International Journal of Advertising, 29(1), pp.85-110.

Msimangira, K. A. B., \& Venkatraman, S. (2014). Supply Chain Management Integration: Critical Problems and Solutions. Operations and Supply Chain Management: An International Journal, 7(1), pp.23-31.

Munson, C. (2013). The Supply Chain Management Casebook: Comprehensive Coverage and Best Practices in SCM. FT Press, Upper Saddle River, NJ.

Munson, C. L., Hu, J., \& Rosenblatt, M. J. (2003). Teaching the costs of uncoordinated supply chains. Interfaces, 33(3), pp.24-39.

Munson, C. L., \& Jackson, J. (2015). Quantity discounts: An overview and practical guide for buyers and sellers, Foundations and Trends in Technology, Information and Operations Management, 8(1/2), pp.1-130.

Nandi, S. (2016). Dynamics of coordination for return policy contracts with warranty. Operations and Supply Chain Management: An International Journal, 9(2), pp.105-118.

Neto, Q. F. J., Bloemhof, J. M., \& Corbett, C. J. (2016). Market prices of remanufactured, used and new items: Evidence from eBay. International Journal of Production Economics, 171(3), pp.371-380.

Nilson, L. B. (2010). Teaching at Its Best (3rd Edition). Published by Jossey-Bass, San Francisco, CA. 
$\mathrm{Xu}$ : Teaching the Mechanism of Horizontal and Vertical Supply Chain Coordination

Okada, E. M. (2005). Justification effects on consumer choice of hedonic and utilitarian goods. Journal of Marketing Research, 42(1), pp.43-53.

Pang, G., Casalin, F., Papagiannidis, S., Muyldermans, L., \& Tse, Y. K. (2015). Price determinants for remanufactured electronic products: a case study on eBay UK. International Journal of Production Research, 53(2), pp.572-589.

Pettersson, A. I., \& Segerstedt, A. (2013). To Evaluate Cost Savings in a Supply Chain: Two Examples from Ericsson in the Telecom Industry. Operations and Supply Chain Management: An International Journal, 6(3), pp.94-102.

Rao, S., Rabinovich, E., \& Raju, D. (2014). The role of physical distribution services as determinants of product returns in Internet retailing, Journal of Operations Management, 32(6), pp.295-312.

Shin, H., \& Tunca, T. I. (2010). Do firms invest in forecasting efficiently? The effect of competition on demand forecast investments and supply chain coordination. Operations Research, 58(6), pp.1592-1610.

Subramanian, R., \& Subramanyam, R. (2002). Key Factors in the Market for Remanufactured Products. Manufacturing and Service Operations Management, 14(2), pp.315-326.

Sweeney, D., Campbell, J., \& Mundy, R. (2010). Teaching supply chain and logistics management through commercial software. The International Journal of Logistics Management, 21(2), pp.293-308.

Talavera, M. G. V. (2014). Supply Chain Collaboration and Trust in the Philippines. Customer-Responsive Supply of Local Foods. Operations and Supply Chain Management: An International Journal, 7(1), pp.1-12.

Xie, J., \& Wei, J. C. (2009). Coordinating advertising and pricing in

a manufacturer-retailer channel. European Journal of Operational Research, 197(2), pp.785-791.

Xu, L., \& Beamon, B. M. (2006). Supply chain coordination and cooperation mechanism: An attribute-based approach. Journal of Supply Chain Management, 42(1), pp.4-12.

Xu, X., \& Gursoy, D. (2015a). A Conceptual Framework of Sustainable Hospitality Supply Chain Management. Journal of Hospitality Marketing and Management, 24(3), pp.229-259.

Xu, X, \& Gursoy D. (2015b). Influence of sustainable hospitality supply chain management on customers' attitudes and behaviors. International Journal of Hospitality Management, 49, pp.105-116.

Xu, X., \& Li, Y. (2016). Examining Key Drivers of Traveler Dissatisfaction with Airline Service Failures: A Text Mining Approach. Journal of Supply Chain and Operations Management, 14(1), pp.30-50.

Ya, D. W. (2015). The comparison of bullwhip effect between AR(1) and ARMA $(1,1)$ demand in supply chain. International Conference on Applied Science and Engineering Innovation, pp.1103-1106.

Yan, R. (2011). Managing channel coordination in a multi-channel manufacturer-retailer supply chain. Industrial Marketing Management, 40(4), pp.636-642.

Yang, B., \& Geunes, J. (2007). Inventory and lead time planning with lead-time-sensitive demand. IEE Transactions, 39(5), pp.432-452.

Zeng, A., \& Johnson, S. (2009). Integrating a discovery-based laboratory to teach supply chain management fundamentals in an undergraduate management course. Innovations in Education and Teaching International, 46(1), pp.71-82.

Xun Xu is currently an Assistant Professor of Operations Management in Department of Management, Operations, and Marketing in College of Business Administration at California State University, Stanislaus in United States. He teaches operations management, management science, materials and inventory management, and other operations management related courses. His research interests include service operations management, supply chain management and coordination, sustainability, e-commerce, data and text mining, and interface of hospitality and operations management. His papers appear on international journals, international conferences proceedings, and book chapters. 